\title{
An Epidemiological Study of Drug Resistance and Resistance Genes in Bovine Escherichia coli Isolates in Heilongjiang Province of China
}

\author{
Jia-San Zheng ${ }^{1,2}$, Ting-Ting Zhu' ${ }^{1}$, Yun Liu' ${ }^{2}$, Ting Lu' ${ }^{2}$, Yan-Qing Li' ${ }^{2}$, Zhen Zhang ${ }^{2}$, Dong-Fang Shi ${ }^{2}$, Jun Bao ${ }^{3} \&$ Li Yu $^{4}$
}

\begin{abstract}
Background: To explore the epidemiology of bovine multidrug-resistant Escherichia coli isolates and resistance genes in Heilongjiang province of China. This study examined the prevalence of genes in bovine $E$. coli isolates, which confer resistance to antibiotics that are commonly used in the clinic, in regions of Baiquan, Shangzhi, and Songbei of Harbin. The purpose of the study was to investigate the epidemiology of the main resistance genes of bovine $E$. coli isolates in clinical veterinary medicine, and to provide a theoretical basis for preventing the spread of drug-resistant bacteria, as well as for rational drug use.

Materials, Methods \& Results: The sensitivity of 105 isolates to 22 antibiotics was determined using the KirbyBauer disk diffusion method, and the distribution of 19 kinds of common drug resistance genes was investigated using Polymerase Chain Reaction. The results showed that the resistance rate to nine antibiotics was over 50\%, including rifampin (84.76\%), ampicillin (73.58\%), tetracycline (69.52\%), and sulfisoxazole (59.05\%). In total, 105 strains of bovine E. coli presented 21 spectra of drug resistance, including eight strains $(7.62 \%, 8 / 105)$ that were resistant to one antibiotic and four strains $(3.81 \%$, 4/105) that were resistant to 21 antibiotics. The resistance gene detection results showed that the streptomycin-resistance gene strA was found in 73 isolates, accounting for $69.52 \%$ of the isolates, followed by the sulfanilamide-resistance genes sul3/sul2 and the aminoglycoside-resistance gene aphA, which accounted for 57.14\%, 51.43\%, and 50.48\%, respectively, of the isolates.
\end{abstract}

Discussion: This study revealed serious drug resistance of bovine $E$. coli isolates in some areas of Heilongiang province. Of $105 \mathrm{E}$. coli isolates, more than $50 \%$ were resistant to the following antibacterial drugs: rifampicin, ampicillin, tetracycline, sulfisoxazole, and cephalothin. The isolates were the most sensitive to amikacin, with a sensitivity of $84.76 \%$, followed by sensitivity to ofloxacin, ciprofloxacin, norfloxacin, cefoxitin, and tobramycin. Drug sensitivity tests showed that the drug resistance spectra of the bovine $E$. coli isolates was different in different regions, indicating that there were multidrug-resistant bovine E. coli isolates in different regions of Heilongjiang province, and that drug resistance differed among different regions. This may be due to prolonged use or overuse of antibiotics in a particular locality. Additionally, because of different management modes of livestock farms, the application of antimicrobial drugs in some farms may have imposed selective pressure on the intestinal flora including E. coli, resulting in the horizontal transmission of drug resistance among the bacteria. The study found that some strains had a resistance phenotype, but no resistance gene, while some had a resistance gene without expressing a resistance phenotype, which is consistent with relevant reports in the literature. This may be related to the same genotype corresponding to different resistance phenotypes, or different levels of gene expression, or different drug metabolic rates. In our study, some strains with certain drug resistance genes were sensitive to the corresponding drug, which may be due to mutations of drug-resistance genes, the loss of a strains resistance phenotype, or the loss of gene function. These issues require further study. This study revealed serious drug resistance of bovine E. coli isolates in some areas of Heilongjiang province. Of $105 \mathrm{E}$. coli isolates, more than $50 \%$ were resistant to the following antibacterial drugs: rifampicin, ampicillin, tetracycline, sulfisoxazole, and cephalothin. The isolates were the most sensitive to amikacin, with a sensitivity of $84.76 \%$, followed by sensitivity to ofloxacin, ciprofloxacin, norfloxacin, cefoxitin, and tobramycin.

Keywords: bovine, Escherichia coli, drug resistance, resistance gene.

DOI: $10.22456 / 1679-9216.79176 .88441$

Received: 7 June 2018

Accepted: 24 0ctober 2018

Published: 5 December 2018

${ }^{1}$ College of Animal Science and Veterinary Medicine, Heilongjiang Bayi Agricultural University, Daqing, China. ${ }^{2}$ College of Veterinary Medicine, Northeast Agricultural University, ${ }^{3}$ College of Animal Science and Technology, Northeast Agricultural University \& ${ }^{4}$ Harbin Veterinary Research Institute, Chinese Academy of Agricultural Sciences, Harbin, China. CORRESPONDENCE: Y. Liu [595095793@qq.com - Tel.: +86 (0451) 55190470]. College of Veterinary Medicine, Northeast Agricultural University. Harbin 150000, China. 


\section{INTRODUCTION}

Escherichia coli is a pathogen that causes anthropozoonoses, which result in serious hazards to the livestock industry, food production, and environmental water sources [4]. E. coli is prone to drug resistance. Drugresistant strains are gradually increasing in the clinic, and the drug resistance spectrum is expanding. Meanwhile, the residual presence of antimicrobial drugs in animals, as well as the spread of drug-resistant strains among different animals, adversely affects the sustainable development of the livestock industry, as well as public health.

The selective pressure of antibiotics can lead to drug-resistant $E$. coli in the gut of animals [20]. In vivo, $E$. coli not only obtains drug resistance through gene mutation and by capturing exogenous genes, but also participates in horizontal and vertical transmission of resistance genes, thus becoming a potential reservoir of drug-resistant genes in animals [18]. E. coli has been identified as an indicator strain for drug resistance tests, which is important for monitoring drug resistance [1]. Therefore, the detection of resistance genes is important to prevent bacterial resistance and to explore the mechanism of bacterial resistance.

This study examined the prevalence of genes in bovine $E$. coli isolates, which confer resistance to antibiotics that are commonly used in the clinic, in three regions Heilongjiang province of China (Baiquan, Shangzhi, and Songbei of Harbin). The purpose of the study was to investigate the epidemiology of the main resistance genes of bovine $E$. coli isolates in clinical veterinary medicine, and to provide a theoretical basis for preventing the spread of drug-resistant bacteria, as well as for rational drug use.

\section{MATERIALS AND METHODS}

\section{Clinical isolates of Escherichia coli strains}

The strains were isolated from rectal swabs and stools from calves with diarrhea and healthy cattle on 5 farms in three regions of Heilongiiang province of China (Baiquan, Shangzhi, and Songbei of Harbin). The samples were streak-inoculated onto MacConkey agar and eosin methylene blue agar and cultured at $37^{\circ} \mathrm{C}$ for $24 \mathrm{~h}$. The resulting colonies were picked and identified as E. coli by biochemistry and Polymerase Chain Reaction. The quality control E. coli strain ATCC 25922 was purchased from the China Industrial Microorganism Culture Collection Center.

Test drugs

Amoxicillin (AMC), ampicillin (AMP), cefoxitin (CFX), ceftriaxone (CRO), ceftazidime (CAZ), cephalo- thin $(\mathrm{CF})$, streptomycin $(\mathrm{S})$, kanamycin $(\mathrm{K})$, gentamicin (GM), tobramycin (TM), amikacin (AMK), sulfamethoxazole (SXT), sulfisoxazole (SIZ), chloramphenicol (C), florfenicol (FFC), ciprofloxacin (CIP), norfloxacin (NOR), ofloxacin (OFL), nalidixic acid (NAL), tetracycline (TC), doxycycline (DOX), and rifampin (RA) ${ }^{1}$.

\section{Drug sensitivity tests}

Drug sensitivity tests were performed with the Kirby-Bauer disk diffusion method using MuellerHinton agar. Bacteria were inoculated into $\mathrm{BHI}^{2}$ medium and shaking-cultured at $37^{\circ} \mathrm{C}$ for $10 \mathrm{~h}$. Then, normal saline was added to adjust the cultures to 0.5 McFarland units, the same as that of the standard tube, for comparative tests. Within 15 min, a sterile cotton swab was dipped into the culture broth and spread on a Mueller-Hinton agar plate ${ }^{2}$. Under aerobic conditions, the plate was cultured at $37^{\circ} \mathrm{C}$ for $24 \mathrm{~h}$. E. coli ATCC 25922 served as a quality control strain, the diameter of the bacteriostatic zone was measured by a Vernier caliper, and the sensitivity of the isolates to antibacterial drugs was assessed according to American Committee for Clinical Laboratory Standards.

\section{Resistance gene testing of isolates}

Based on the drug resistance mechanisms of E. coli against $\beta$-lactams, aminoglycosides, tetracyclines, streptomycin, sulfonamides, quinolones, and chloramphenicol, 19 resistance genes, including SHV genes, floR, and aacA4, were selected to analyze the genotypes of the resistance genes from the bovine E. coli isolates. Amplification products were processed via $1.0 \%$ agarose gel electrophoresis $\left(1 \times \mathrm{TAE}^{3}\right.$, with ethidium bromide $(\mathrm{EB})^{3}$ staining, for $20 \mathrm{~min}$ at $120 \mathrm{~V}$ ) and photographed with a gel-documenting system ${ }^{4}$. PCR primers and annealing temperatures are shown in Table 1.

\section{RESULTS}

\section{Drug sensitivity of bovine Escherichia coli isolates}

A total of 105 bovine E. coli strains showed varying degrees of resistance to 22 antibiotics, among which the resistance rates to 7 antibacterial drugs were greater than $50 \%$. The resistance rate to RA was the highest, $84.76 \%$, followed by AMP (73.58\%), TC $(69.52 \%)$, and SIZ (59.05\%). The sensitivity rates of the strains to 14 antibacterial drugs were more than $50 \%$, ranked as follows: AMK $(84.76 \%)$, OFL $(80.00 \%)$, CIP $(76.92 \%)$, NOR $(76.19 \%)$, and FFC (75.24\%). The details are listed in Table 2. 
J.S.Zheng, T.T.Zhu, Y. Liu, et al. 2018. An Epidemiological Study of Drug Resistance and Resistance Genes in Bovine Escherichia coli Isolates in Heilongjiang Province of China. Acta Scientiae Veterinariae. 46: 1611.

Table 1. Primers used in Resistance gene detection of Escherichia coli isolated from cattle.

\begin{tabular}{|c|c|c|c|c|}
\hline $\begin{array}{l}\text { Antimicrobial } \\
\text { family and gene }\end{array}$ & Sequence $\left(5^{\prime}-3^{\prime}\right)$ & Amplicon size (bp) & Annealing $\mathrm{T}$ & GenBank accession no. \\
\hline bla-CMY-2 & $\begin{array}{l}\text { GACAGCCTCTTTCTCCACA } \\
\text { TGGAACGAAGGCTACGTA }\end{array}$ & 1014 & 56 & NG_041242.1 \\
\hline bla-TEM & $\begin{array}{l}\text { ATGAGTATTCAACATTTCCG } \\
\text { CTGACAGTACCAATGCTTA }\end{array}$ & 860 & 58 & AF309824 \\
\hline bla-SHV & $\begin{array}{l}\text { TCGCCTGTGTATTATCTCCC } \\
\text { CGCAGATAAATCACCACAATG }\end{array}$ & 873 & 56 & AF148850 \\
\hline bla-CTX & $\begin{array}{l}\text { CGATGTGCAGTACCAGTA A } \\
\text { TTAGTGACAGAATCAGCGG }\end{array}$ & 566 & 57 & JN411912.1 \\
\hline strA & $\begin{array}{l}\text { CCTGGTGATAACGGCAATTC } \\
\text { CCAATCGCAGATAGAAGGC }\end{array}$ & 539 & 56 & EF090911.1 \\
\hline $\operatorname{strB}$ & $\begin{array}{l}\text { ATCGTCAGGGATTGAAACC } \\
\text { GGATCGTAGAACATATTGGC }\end{array}$ & 489 & 57 & EF090911.1 \\
\hline tet $\mathrm{A}$ & $\begin{array}{l}\text { CGGCAGGCAGAGCAAGTAGA } \\
\text { GGCGGTCTTCTTCATCATGC }\end{array}$ & 482 & 58 & X54723 \\
\hline tetB & $\begin{array}{l}\text { CATTAATAGGCGCATCGCTG } \\
\text { TGAAGGTATCGATAGCAGG }\end{array}$ & 514 & 56 & EF646764.1 \\
\hline Sul1 & $\begin{array}{l}\text { TTCGGCATTCTGAATCTCAC } \\
\text { ATGATCTAACCCTCGGTCTC }\end{array}$ & 770 & 58 & M62822 \\
\hline Sul2 & $\begin{array}{l}\text { CGGCATCGTCAACATAACCT } \\
\text { TGTGCGGATGAAGTCAGCTC }\end{array}$ & 720 & 58 & X53796 \\
\hline Sul3 & $\begin{array}{l}\text { ACCTAAGAATGATTTCCGTGAC } \\
\text { ACTGAAGTGGGCGTTGTG }\end{array}$ & 313 & 57 & AY494779.1 \\
\hline floR & $\begin{array}{l}\text { ACGTTTATGCCAACCGTCCTG } \\
\text { AAAGTGCCACCGCCAATGTCC }\end{array}$ & 495 & 58 & X00006 \\
\hline $\operatorname{clmA}$ & $\begin{array}{l}\text { CGCCCGGACTAATGAT } \\
\text { GCAATAAAGCCTAACACG }\end{array}$ & 229 & 56 & AB212941.1 \\
\hline Apha1 & $\begin{array}{l}\text { CATGACCTTGCGATGCTCT } \\
\text { CTGGTCTATTCCGCGTACTCC }\end{array}$ & 258 & 55 & X92506 \\
\hline aadB & $\begin{array}{l}\text { TGTAACACGCAAGCACGATG } \\
\text { AACCTTTTCCGCCCCGAGT }\end{array}$ & 285 & 58 & NG_035375.1 \\
\hline aacA4 & $\begin{array}{l}\text { CATGACCTTGCGATGCTCT } \\
\text { CTGGTCTATTCCGCGTACTCC }\end{array}$ & 635 & 56 & KC417377.1 \\
\hline qnrA & $\begin{array}{l}\text { TCAGCAAGAGGATTTCTCA } \\
\text { GGCAGCACTATTACTCCCA }\end{array}$ & 627 & 55 & KC493118.1 \\
\hline qnrS & $\begin{array}{l}\text { GCAAGTTCATTGAACAGGGT } \\
\text { TCTAAACCGTCGAGTTCGGCG }\end{array}$ & 428 & 58 & NG_039601.1 \\
\hline qepA & $\begin{array}{l}\text { GCAGGTCCAGCAGCGGGTAG } \\
\text { CTTCCTGCCCGAGTATCGTG }\end{array}$ & 199 & 55 & FJ167861.1 \\
\hline
\end{tabular}


J.S.Zheng, T.T.Zhu, Y. Liu, et al. 2018. An Epidemiological Study of Drug Resistance and Resistance Genes in Bovine Escherichia coli

Table 2. The results of drug sensitivity test of 105 Escherichia coli isolated from cattle.

\begin{tabular}{|c|c|c|c|c|c|c|c|}
\hline \multicolumn{2}{|c|}{ Antimicrobial } & Resistant & Intermediate & Sensitive & $\begin{array}{l}\text { Sensitive } \\
\text { rate }\end{array}$ & $\begin{array}{l}\text { Intermediary } \\
\text { rate }\end{array}$ & $\begin{array}{l}\text { Resistance } \\
\text { rate }\end{array}$ \\
\hline \multirow{6}{*}{$\beta$-lactams } & $\mathrm{AMC}$ & 37 & 10 & 58 & $55.24 \%$ & $9.52 \%$ & $35.24 \%$ \\
\hline & AMP & 78 & 4 & 23 & $21.90 \%$ & $3.81 \%$ & $74.29 \%$ \\
\hline & CFX & 18 & 8 & 79 & $75.24 \%$ & $7.62 \%$ & $17.14 \%$ \\
\hline & $\mathrm{CRO}$ & 50 & 8 & 47 & $44.76 \%$ & $7.62 \%$ & $47.62 \%$ \\
\hline & CAZ & 20 & 10 & 75 & $71.43 \%$ & $9.52 \%$ & $19.05 \%$ \\
\hline & $\mathrm{CF}$ & 57 & 12 & 36 & $34.29 \%$ & $11.43 \%$ & $54.29 \%$ \\
\hline \multirow{5}{*}{ Aminoglycosides } & $\mathrm{S}$ & 51 & 13 & 41 & $39.05 \%$ & $12.38 \%$ & $48.57 \%$ \\
\hline & $\mathrm{K}$ & 43 & 7 & 55 & $52.38 \%$ & $6.67 \%$ & $40.95 \%$ \\
\hline & GM & 30 & 3 & 72 & $68.57 \%$ & $2.86 \%$ & $28.57 \%$ \\
\hline & $\mathrm{TM}$ & 22 & 7 & 76 & $72.38 \%$ & $6.67 \%$ & $20.95 \%$ \\
\hline & AMK & 7 & 4 & 94 & $89.52 \%$ & $3.81 \%$ & $6.67 \%$ \\
\hline \multirow{2}{*}{ Sulfonamides } & SXT & 44 & 2 & 59 & $56.19 \%$ & $1.90 \%$ & $41.90 \%$ \\
\hline & $\mathrm{SIZ}$ & 62 & 0 & 43 & $40.95 \%$ & $0.00 \%$ & $59.05 \%$ \\
\hline \multirow{2}{*}{ Chloramphenicols } & $\mathrm{C}$ & 41 & 8 & 56 & $53.33 \%$ & $7.62 \%$ & $39.05 \%$ \\
\hline & FFC & 24 & 2 & 79 & $75.24 \%$ & $1.90 \%$ & $22.86 \%$ \\
\hline \multirow{4}{*}{ Quinolones } & CIP & 22 & 1 & 80 & $77.67 \%$ & $0.97 \%$ & $21.36 \%$ \\
\hline & NOR & 22 & 3 & 80 & $76.19 \%$ & $2.86 \%$ & $20.95 \%$ \\
\hline & OFL & 19 & 2 & 84 & $80.00 \%$ & $1.90 \%$ & $18.10 \%$ \\
\hline & NAL & 41 & 3 & 61 & $58.10 \%$ & $2.86 \%$ & $39.05 \%$ \\
\hline \multirow{2}{*}{ Tetracyclines } & $\mathrm{TC}$ & 63 & 3 & 39 & $37.14 \%$ & $2.86 \%$ & $60.00 \%$ \\
\hline & DOX & 40 & 3 & 62 & $59.05 \%$ & $2.86 \%$ & $38.10 \%$ \\
\hline Rifamycin & RA & 89 & 10 & 6 & $5.71 \%$ & $9.52 \%$ & $84.76 \%$ \\
\hline
\end{tabular}

Amoxicillin (AMC), ampicillin (AMP), cefoxitin (CFX), ceftriaxone (CRO), ceftazidime (CAZ), cephalothin (CF), streptomycin (S), kanamycin (K), gentamicin (GM), tobramycin (TM), amikacin (AMK), sulfamethoxazole (SXT), sulfisoxazole (SIZ), chloramphenicol (C), florfenicol (FFC), ciprofloxacin (CIP), norfloxacin (NOR), ofloxacin (OFL), nalidixic acid (NAL), tetracycline (TC), doxycycline (DOX), and rifampin (RA).

Drug resistance spectra of bovine Escherichia coli isolates in different regions

In three areas of Heilongjiang province, a total of 105 bovine $E$. coli strains showed 21 drug resistance spectra, in which 8 strains $(7.62 \%, 8 / 105)$ were resistant to $1 \mathrm{drug}$, and 4 strains $(3.81 \%, 4 / 105)$ were resistant to 21 drugs. In the Shangzhi area, strains resistant to 13 or 15 drugs accounted for $15.91 \%$ of the strains, while strains resistant to 17,19 , or 1 drug accounted for $11.36 \%$ of the strains. In the Baiquan area, $34.88 \%$ of the strains were resistant to one drug, followed by strains resistant to 5,3 , or 13 drugs, accounting for $25.58 \%, 23.26 \%$, and $9.30 \%$ of the strains, respectively. In the Songbei area, strains resistant to 7 or 11 drugs accounted for $22.22 \%$ of the strains, followed by strains resistant to $9(16.67 \%), 15(11.11 \%)$, and 19 drugs $(11.11 \%)$ [Figure 1$].$

Resistance phenotypes of bovine Escherichia coli

Of the 105 bovine $E$. coli isolates, there were mainly 15 resistance phenotypes to nine antibiotics.
$\mathrm{AMP}+\mathrm{S}+\mathrm{TC}+\mathrm{C}+\mathrm{SIZ}$ and $\mathrm{AMP}+\mathrm{SIZ}$ resistant phenotypes accounted for $10.48 \%$ of the isolates (the maximal proportion), followed by resistance to AMP $+\mathrm{CF}+\mathrm{SIZ}+\mathrm{S}+\mathrm{TC}, \mathrm{AMP}+\mathrm{CF}+\mathrm{SIZ}+\mathrm{TC}+\mathrm{S}+$ $\mathrm{GM}$, or $\mathrm{AMP}+\mathrm{CF}+\mathrm{TC}+\mathrm{S}+\mathrm{GM}+\mathrm{C}$, accounting for $8.57 \%$ of the total isolates (Table 3 ).

Resistance genes of bovine Escherichia coli isolates

Of the 105 bovine $E$. coli isolates, the test results for 19 resistance genes in 7 categories showed that the sulfonamide-resistant gene sul3 was the most widely distributed, as it was found in 30 isolates ( $28.57 \%$ ), followed by the chloramphenicol-resistant gene floR, which was found in 28 strains (26.67\%), the $\beta$-lactam-resistant gene blaTEM (25 strains, 23.18\%), and the streptomycin-resistant gene strA (20 strains, $19.05 \%)$. Five strains carried the quinolone-resistant gene qepA, accounting for $4.76 \%$ of the strains (the lowest frequency), followed by the sulfonamideresistant gene sul1 (6.67\%) and the chloramphenicolresistant gene clmA $(7.62 \%)$ [Table 4$]$. 


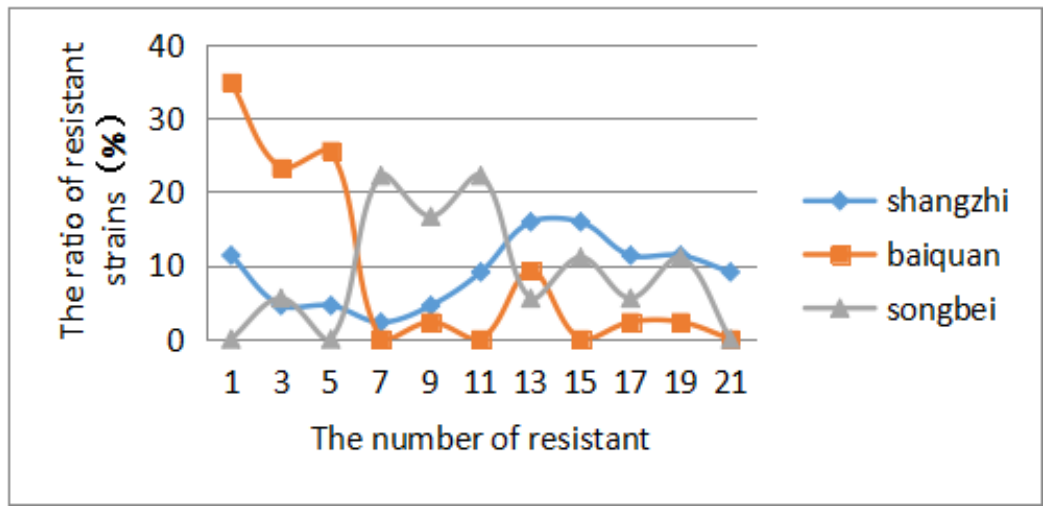

Figure 1. Drug resistance spectrum of Escherichia coli from cattle in different areas of Heilongjiang province of China

Table 3. Nine kinds of antimicrobial drug resistance phenotype of 105 Escherichia coli isolated from cattle.

\begin{tabular}{ccc}
\hline Phenotypic resistance & Isolates & Percentage \\
\hline AMP+CF & 8 & $7.62 \%$ \\
AMP+SIZ & 11 & $10.48 \%$ \\
AMP+CF+S+SIZ & 7 & $6.67 \%$ \\
AMP+CF+SIZ+S+TC & 9 & $8.57 \%$ \\
AMP+SIZ+S+TC+GM & 7 & $6.67 \%$ \\
AMP+S+TC+C+SIZ & 11 & $10.48 \%$ \\
AMP+CF+SIZ+TC+S+GM & 9 & $8.57 \%$ \\
AMP+CF+TC+S+GM+C & 9 & $8.57 \%$ \\
AMP+CF+TC+S+GM+C+SIZ+CIP & 5 & $4.76 \%$ \\
AMP+TC+S+C+SIZ+CIP & 4 & $3.81 \%$ \\
CF+TC+GM & 2 & $1.90 \%$ \\
CF+S+TC+C & 5 & $4.76 \%$ \\
CF+S+TC+C+SIZ & 8 & $7.62 \%$ \\
CF+S+TC+C+GM +SIZ & 8 & $7.62 \%$ \\
AMP+CF+S+C+GM+TC+SIZ+CIP+AMK & 2 & $1.90 \%$ \\
\hline
\end{tabular}

Ampicillin (AMP); cephalothin (CF); sulfisoxazole (SIZ); streptomycin (S); tetracycline (TC); gentamicin (GM); chloramphenicol (C); streptomycin (S); ciprofloxacin (CIP).

Table 4. Carrier rate of different resistant genes of 105 Escherichia coli isolated from cattle.

\begin{tabular}{ccc}
\hline Resistance gene & Isolates & Carrier rate \\
\hline blaCTX & 0 & $0.00 \%$ \\
blaCMY & 16 & $15.24 \%$ \\
blaTME & 25 & $23.81 \%$ \\
blaSHV & 9 & $8.57 \%$ \\
aacA4 & 19 & $18.10 \%$ \\
aphA & 11 & $10.48 \%$ \\
aadB & 16 & $15.24 \%$ \\
sul1 & 7 & $6.67 \%$ \\
sul2 & 15 & $14.29 \%$ \\
sul3 & 30 & $28.57 \%$ \\
tetA & 17 & $16.19 \%$ \\
tetB & 11 & $10.48 \%$ \\
floR & 28 & $26.67 \%$ \\
clmA & 8 & $7.62 \%$ \\
qnrs & 16 & $15.24 \%$ \\
qnrA & 9 & $8.57 \%$ \\
qepA & 5 & $4.76 \%$ \\
strA & 20 & $19.05 \%$ \\
strB & 17 & $16.19 \%$ \\
\hline
\end{tabular}


Resistance genotypes of bovine Escherichia coli isolates from different areas

Of the 105 bovine E. coli isolates from the 3 areas, there were 7 kinds of resistant genotypes, including resistance to $\beta$-lactams, aminoglycosides, sulfonamides, tetracycline, chloramphenicol, quinolones, and streptomycin. Despite the presence of the same genotypes in all three areas, there were some differences between the different areas regarding the number of isolates carrying drug resistance genes (Table 5).
Correlation between resistance phenotype and resistance genes

Consistency analysis of the resistance phenotypes and the resistance genes to nine antibiotics showed that sulfamethoxazole had the highest consistency ( $83.87 \%)$, followed by chloramphenicol $(68.29 \%)$, while norfloxacin had the lowest consistency $(22.72 \%)$. It was observed that some isolates presented drug resistance without carrying resistance genes, whereas some isolates carried resistance genes without manifesting a resistance phenotype (Table 6).

Table 5. The distribution of resistant genes of Escherichia coli isolated from cattle fom regions of Baiquan, Shangzhi, and Songbei of Harbin - Heilongjiang province of China.

\begin{tabular}{|c|c|c|c|c|c|c|c|c|c|c|c|c|c|c|c|c|c|c|c|}
\hline \multirow{2}{*}{ GeneType } & \multicolumn{4}{|c|}{$\beta$-lactams } & \multicolumn{3}{|c|}{ Aminoglycosides } & \multicolumn{3}{|c|}{ Sulfonamides } & \multicolumn{2}{|c|}{ Tetracyclines } & \multicolumn{2}{|c|}{ Chloramphenicols } & \multicolumn{3}{|c|}{ Quinolones } & \multicolumn{2}{|c|}{ Streptomycin } \\
\hline & CTX & CMY & TME & SHV & aacA4 & aphA & aadB & sul & sul2 & sul3 & tet $\mathrm{A}$ & tetB & floR & $\operatorname{clm} A$ & qnrs & qnrA & qepA & $\operatorname{str} \mathrm{A}$ & strB \\
\hline shangzhi & 0 & 13 & 12 & 6 & 10 & 9 & 6 & 4 & 7 & 15 & 13 & 0 & 19 & 7 & 14 & 5 & 2 & 12 & 11 \\
\hline baiquan & 0 & 3 & 8 & 3 & 5 & 2 & 6 & 3 & 6 & 7 & 2 & 4 & 3 & 1 & 2 & 1 & 0 & 3 & 1 \\
\hline songbei & 0 & 0 & 5 & 0 & 4 & 0 & 4 & 0 & 2 & 8 & 2 & 7 & 6 & 0 & 0 & 3 & 3 & 5 & 5 \\
\hline
\end{tabular}

Table 6. Comparison of consistency in Escherichia coli isolates according to phenotypic and genotypic testing.

\begin{tabular}{|c|c|c|c|c|c|c|}
\hline \multirow{2}{*}{ Antimicrobial } & \multicolumn{6}{|c|}{ Characteristics of isolate } \\
\hline & $\mathrm{N}_{\mathrm{P}}{ }^{*}$ & Gene(s) carried & $\mathrm{N}_{\mathrm{G}} *$ & consistency & $\mathrm{P}+/ \mathrm{G}-{ }^{*}$ & $\mathrm{P}-/ \mathrm{G}+{ }^{*}$ \\
\hline Ampicillin & 78 & $\begin{array}{l}\text { blaTEM } \\
\text { blaSHV }\end{array}$ & $\begin{array}{c}25 \\
9 \\
34\end{array}$ & $43.59 \%$ & 58 & $\begin{array}{l}2 \\
3\end{array}$ \\
\hline Cefalotin & 57 & blaCMY-2 & $\begin{array}{l}21 \\
21\end{array}$ & $36.84 \%$ & 29 & 0 \\
\hline Sulfamethoxazole & 62 & $\begin{array}{l}\text { sul1 } \\
\text { sul2 } \\
\text { sul3 }\end{array}$ & $\begin{array}{c}7 \\
15 \\
30 \\
52\end{array}$ & $83.87 \%$ & 8 & $\begin{array}{l}0 \\
3 \\
9\end{array}$ \\
\hline Kanamycin & 43 & $\begin{array}{l}\operatorname{aphA} \\
\operatorname{aadB}\end{array}$ & $\begin{array}{l}11 \\
16 \\
27\end{array}$ & $62.80 \%$ & 30 & $\begin{array}{l}3 \\
7\end{array}$ \\
\hline chloramphenicol & 41 & floR & $\begin{array}{l}28 \\
28\end{array}$ & $68.29 \%$ & 10 & $\begin{array}{l}1 \\
2\end{array}$ \\
\hline norfloxacin & 22 & qepA & $\begin{array}{l}5 \\
5\end{array}$ & $22.72 \%$ & 8 & 1 \\
\hline tetracycline & 63 & $\begin{array}{l}\text { tetA } \\
\text { tetB }\end{array}$ & $\begin{array}{l}17 \\
11 \\
28\end{array}$ & $44.44 \%$ & 23 & 2 \\
\hline streptomycin & 51 & $\begin{array}{l}\text { strA } \\
\text { strB }\end{array}$ & $\begin{array}{l}20 \\
17 \\
37 \\
\end{array}$ & $72.55 \%$ & 17 & 5 \\
\hline
\end{tabular}

$\mathrm{N}_{\mathrm{p}}^{*}$ : number of $E$. coli isolates expressing phenotypic resistance to the indicated antimicrobial agent; $\mathrm{N}_{\mathrm{G}}{ }^{*}:$ number of $E$. coli isolates carrying the indicated resistance gene; $\mathrm{P}+/ \mathrm{G}^{*}{ }^{*}$ : number of phenotypically resistant $E$. coli isolates $(\mathrm{P}+)$ with no resistance gene (G-) for the drug identified; $\mathrm{P}-/ \mathrm{G}+^{*}$ : number of phenotypically susceptible $E$. coli isolates $(\mathrm{P}-)$ with a resistance gene $(\mathrm{G}+)$ for the drug identified. 


\section{DISCUSSION}

The drug resistance of Escherichia coli is mainly acquired via mutation or the capture of exogenous resistance genes by plasmids, transposons, and other removable fragments, and exogenous genes play a major role in bacterial resistance [19].

$\beta$-lactamase plays a key role in the drug resistance of E. coli to broad-spectrum $\beta$-lactams $[3,12]$. This study examined four kinds of $\beta$-lactam-resistance genes and found that more isolates carried blaTEM and blaCMY genes, while fewer isolates carried blaCTX and blaSHV genes. Of the 105 bovine $E$. coli isolates in our study, the overall detection rate of blaTEM was $15.24 \%(16 / 105)$, which was higher than that reported in China a few years ago [6,23], indicating that due to the increased use of cephalosporins, there was a rising trend of extended spectrum $\beta$ lactamases (ESBLs) produced by bovine $E$. coli isolates.

The aminoglycoside-resistance gene aacA4 had the highest detection rate, and the resistance genes aacA4, aphA, and aadB were detected in all three regions, which was different from a previous report. This suggests that there are some differences in the distribution of aminoglycoside-resistance genes in different regions.

The streptomycin-resistance genes strA and strB co-mediate the streptomycin-resistance phenotype [17]. In this study, the detection rates of strA and strB were $19.05 \%$ and $16.19 \%$, respectively, indicating that almost all strains carrying strA also carried strB; thus, the consistency of the results was good.

It was reported that the most common tetracycline-resistance phenotype had more than 40 kinds of coding genes, but the two efflux pump genes, tetA and tetB, accounted for $90 \%$ of the resistance [16], which was also reported in gut commensal E. coli and pathogenic E. coli $[10,11]$. In this study, the detection rates of tet $\mathrm{A}$ and tetB were $16.19 \%$ and $10.48 \%$, respectively. However, only tetA was detected when testing tetracycline-resistance genes in the Sangzhi area, probably because the incompatibility between plasmids resulted in a negative correlation between tetB and tetA [2].

The test results for the chloramphenicol resistant genes floR and clmA showed that although chloramphenicol use is forbidden in livestock animals in China, the survey found a high degree of resistance to chloramphenicol, with a positive rate of $34.29 \%$.
We suspected that the genes encoding chloramphenicol resistance were co-screened and preserved under selective pressure related to other antimicrobial agents. One study demonstrated that strains carrying floR also showed resistance to chloramphenicol, while strains carrying cmlA were not $100 \%$ resistant to florfenicol [22], which was consistent with the results of our study. Therefore, the mechanism of chloramphenicol resistance still needs to be further explored.

The results of sulfonamide-resistance gene tests showed that the detection rates of sul1, sul2, and sul3 were $6.67 \%, 14.29 \%$, and $28.57 \%$, respectively. In 2003, sul3 was first discovered by Perreten et al. [13]. Afterwards, sul3 was found in E. coli strains in many countries. It was reported $[7,8]$ that the main sulfonamide-resistance genes in bovine $E$. coli isolates were sul1 and sul2; the detection rate of sul2 was two to five times that of sul1, and only a few sul 3 genes were observed. This was quite different from our study, in which the detection rate of sul3 was the highest, and the detection rate of sul2 was two times higher than that of sull.

Since 1998, three plasmid-mediated quinolone resistance determinants including qnr genes (qnrA, qnrB, qnrS), aac(6')-Ib-cr, and qepA, have been reported in various Enterobacteriaceae genera worldwide [9]. qnr encodes the QNR protein, which can protect DNA gyrase and topoisomerase IV from inhibition by quinolones; a qepA-encoded plasmid-mediated efflux pump can mediate low-level drug resistance by excreting hydrophilic quinolones [15]. In this study, the detection rates of qnrS, qnrA, and qepA in 105 bovine E. coli isolates were $15.24 \%, 8.57 \%$, and $4.76 \%$, respectively, indicating that PMQR gene is prevalent in Heilongjiang province, and that qnrS is the dominant type. This is different from reports in recent years [14], which may be due to the different sources of strains and different medications. Studies have shown that qnr plasmids often carry integrons, transposons, and multi-drug resistance gene determinants, especially associated with ESBL-producing genes, which are helpful for the horizontal or vertical transmission of resistance genes among bacteria in the same or different genus under the selective pressure of different drugs [5]. Therefore, how to promote the scientific and rational use of quinolones to reduce the production of quinolone-resistant strains becomes an important issue in future research. 


\section{CONCLUSIONS}

The results showed that drug-resistant bovine E. coli isolates were common in Heilongjiang province. Additionally, these isolates possessed diverse and complex drug resistance phenotypes, and drug resistance genes were widely distributed in drugresistant strains; however, no significant association was observed between the drug resistance phenotype and resistance genes.

MANUFACTURERS

${ }^{1}$ Kangtai Biological Products Co., Ltd. Shenzhen, China.
${ }^{2}$ Hopebio. QingDao, China.

${ }^{3}$ Sigma-Aldrich Co. St. Louis, MO, USA.

${ }^{4}$ Sage Creation. Beijing, China.

Acknowledgements. This research was supported by State Key Laboratory of Veterinary Biotechnology (grant No. SKLVBF201303), The National Science and Technology Program of China (grant No. 2012BAD12B03, grant No. 2012BAD12B05).

Declaration of interest. The authors report no conflict interest. The authors alone are responsible for the content and writing of paper.

\section{REFERENCES}

1 Aubry-Damon H., Grenet K., Sall-Ndiaye P., Che D., Cordeiro E., Bougnoux M.E. \& Andremont A. 2004. Antimicrobial resistance in commensal flora of pig farmers. Emerging Infectious Diseases. 10(5): 873-879.

2 Boerlin P., Travis R., Gyles C.L., Reid-Smith R., Lim N.J.H., Nicholson V. \& Archambault M. 2005. Antimicrobial resistance and virulence genes of Escherichia coli isolates from swine in Ontario. Applied \& Environmental Microbiology. 71(11): 6753-6761.

3 Bradford P.A. 2001. Extended-spectrum $\beta$-lactamases in the 21st century: characterization, epidemiology, and detection of this important resistance threat. Clinical Microbiology Reviews. 14(4): 933-951.

4 Caprioli A., Morabito S., Brugère H. \& Oswald E. 2005. Enterohaemorrhagic Escherichia coli: emerging issues on virulence and modes of transmission. Veterinary Research. 36(3): 289-311.

5 Chen Y.T., Shu H.Y., Li L. H., Liao T.L., Wu K.M. \& Shiau Y.R., Yan J.J., Su I.J., Tsai S.F. \& Lauderdale T.L. 2006. Complete nucleotide sequence of pK245, a 98-kilobase plasmid conferring quinolone resistance and extendedspectrum- $\beta$-lactamase activity in a clinical Klebsiella pneumoniae isolate. Antimicrobial Agents \& Chemotherapy. 50(11): 3861-3866.

6 Di L.N., Nan H.C., Xia L.N. \& Wang J. 2014. Detection of $\beta$-Lactamase and 16S rRNA Methylase Gene in Resistant Escherichia coli Isolates from Cattle and Sheep in Xinjiang. Chinese Agricultural Science Bulletin. 30(35): 87-92.

7 Gow S.P., Waldner C.L., Harel J. \& Boerlin P. 2008. Associations between antimicrobial resistance genes in fecal generic Escherichia coli isolates from cow-calf herds in western Canada. Applied \& Environmental Microbiology. 74(12): 3658-3666.

8 Guerra B., Junker E., Schroeter A., Malorny B., Lehmann S. \& Helmuth R. 2003. Phenotypic and genotypic characterization of antimicrobial resistance in German Escherichia coli isolates from cattle, swine and poultry. International Journal of Infectious Diseases. 52(3): 489-492.

9 Ma J., Zeng Z., Che, Z., Xu X., Wang X., Deng Y. \& Wang M. 2009. High prevalence of plasmid-mediated quinolone resistance determinants qnr, aac (6')-Ib-cr, and qepA among ceftiofur-resistant Enterobacteriaceae isolates from companion and food-producing animals. Antimicrobial Agents \& Chemotherapy. 53(2): 519-524.

10 Maynard C., Fairbrother J.M., Bekal S., Sanschagrin F., Levesque R.C., Brousseau R. \& Harel J. 2003. Antimicrobial resistance genes in enterotoxigenic Escherichia coli O149: K91 isolates obtained over a 23-year period from pigs. Antimicrobial Agents \& Chemotherapy. 47(10): 3214-3221.

11 Medina A., Horcajo P., Jurado S., De La Fuente R., Ruiz-Santa-Quiteria J.A., Domínguez-Bernal G. \& Orden J.A. 2011. Phenotypic and genotypic characterization of antimicrobial resistance in enterohemorrhagic Escherichia coli and atypical enteropathogenic E. coli strains from ruminants. Journal of Veterinary Diagnostic Investigation. 23(1): 91-95.

12 Nordmann P. 1998. Trends in $\beta$-lactam resistance among Enterobacteriaceae. Clinical Infectious Diseases. 27(1): 100-106.

13 Perreten V. \& Boerlin P. 2003. A new sulfonamide resistance gene (sul3) in Escherichia coli is widespread in the pig population of Switzerland. Antimicrobial Agents \& Chemotherapy. 47(3): 1169-1172. 
14 Robicsek A., Strahilevitz J., Sahm D.F., Jacoby G.A. \& Hooper D.C. 2006. qnr prevalence in ceftazidime-resistant Enterobacteriaceae isolates from the United States. Antimicrobial Agents \& Chemotherapy. 50(8): 2872-2874.

15 Strahilevitz J., Jacoby G.A., Hooper D.C. \& Robicsek A. 2009. Plasmid-mediated quinolone resistance: a multifaceted threat. Clinical microbiology reviews. 22(4): 664-689.

16 Rosengren L.B., Waldner C.L. \& Reid-Smith R.J. 2009. Associations between antimicrobial resistance phenotypes, antimicrobial resistance genes, and virulence genes of fecal Escherichia coli isolates from healthy grow-finish pigs. Applied \& Environmental Microbiology. 75(5): 1373-1380.

17 Sundin G.W. \& Bender C.L. 2010. Dissemination of the strA-strB streptomycin-resistance genes among commensal and pathogenic bacteria from humans, animals, and plants. Molecular Ecology. 5(1): 133-143.

18 Tang J.Y., Wang H.N., Zhang P.J., Gang T.T. \& Zeng B. 2008. Phenotypic and aminoglycosides genotypic antimicrobial resistance characterization of Escherichia coli isolated from 95 pig farms. Chinese Journal of Animal \& Veterinary Sciences. 39(4): 472-477.

19 Tenover F.C. 2006. Mechanisms of antimicrobial resistance in bacteria. American Journal of Infection Control. 119(6): S3-S10.

20 Teuber M. 2001. Veterinary use and antibiotic resistance. Current Opinion in Microbiology. 4(5): 493-499.

21 Wu C.M., Wang Y., Cao X.Y., Lin J.C., Qin S.S., Mi T.J. \& Shen J.Z. 2009. Emergence of plasmid-mediated quinolone resistance genes in Enterobacteriaceae isolated from chickens in China. Journal of Antimicrobial Chemotherapy. 63(2): 408-411.

22 Yang X., Wang H.N., Zhang A.Y., Xia Q.Q. \& Zeng B. 2009. Development of multiplex PCR detecting kit and its application to the detection of chloramphenicols resistant genes in Escherichia coli. Chinese Journal of Veterinary Medicine. 45(2): 11-13.

23 Zhang Z.Z., Wu J.W., Wei S.Y., Tang J.H., Chen H.W. \& Li S. 2009. Analysis of Genotype of Escherichia coli producing ESBLs and AmpC $\beta$-lactamases Isolated from Farm Animals. Chinese Journal of Animal \& Veterinary Sciences. 117(24): 5721-5729. 